\title{
Case Report: Hydranencephaly in a female newborn with
}

\section{congenital cytomegalovirus infection [version 1; peer review:}

\section{1 approved with reservations]}

\section{Lilia Dewiyanti1,2, Andrew Robert Diyo3 ${ }^{3}$, Jonathan Edbert Afandy (iD1,2, Jennefer .1,2, Cipta Pramana (1D) 4}

\author{
${ }^{1}$ Department of Pediatrics, KRMT Wongsonegoro Hospital, Semarang, Central Java, 50272, Indonesia \\ ${ }^{2}$ Department of Pediatrics, Medical Faculty Tarumanagara University, Jakarta, DKI, 11440, Indonesia \\ ${ }^{3}$ Department of Neurosurgery, KRMT Wongsonegoro Hospital, Semarang, Central Java, 50272, Indonesia \\ ${ }^{4}$ Department of Obstetrics and Gynecology, Faculty of Medicine, KRMT Wongsonegoro Hospital, Jakarta, DKI, 11440, Indonesia
}

V1 First published: 16 Feb 2022, 11:199

https://doi.org/10.12688/f1000research.108934.1

Latest published: 13 Jun 2022, 11:199

https://doi.org/10.12688/f1000research.108934.2

\section{Abstract}

Background: Hydranencephaly is a congenital abnormality of the central nervous system characterized by massive hemispheric necrosis and ventricular dilatation with most of the cerebral hemispheres being replaced by membranous sacs filled with cerebrospinal fluid (CSF). Cytomegalovirus (CMV) infection can be one of the causes of hydranencephaly. The choice of therapy for hydranencephaly is a challenge because of poor prognosis, but now neural stem cell (NSC) transplantation may give new hope.

Case report: We report a case of a female newborn born at term by cesarean section from a gravida 5, para 3, abortus 1 (G5P3A1) mother with suspected hydrocephalus. Head circumference was $35 \mathrm{~cm}$ at birth. The baby was born crying immediately, looked active, and did not appear cyanotic, but on the second day, the baby looked less active, moaned, showed acral cyanosis, and had a large fontanelle that was dilated and soft. Signs of hydrocephalus such as Macewen's sign, setting sun phenomenon, and transillumination were found to be positive. Echocardiographic examination showed floppy interatrial septum and mild mitral regurgitation. Non-contrast computerized tomography (CT) scan of the head showed hydranencephaly. The toxoplasmosis, rubella, CMV, and herpes simplex virus (TORCH) screening showed positive anti-CMV immunoglobulin G (IgG). The baby underwent a ventriculoperitoneal (VP) shunt procedure with a head circumference of $36 \mathrm{~cm}$ before surgery. VP shunt was performed with an opening pressure of $15 \mathrm{cmH}_{2} \mathrm{O}$.

Conclusions: After the VP shunt procedure, the baby's general condition improved with the head circumference within normal limits. The baby was discharged from the hospital after 16 days of treatment.

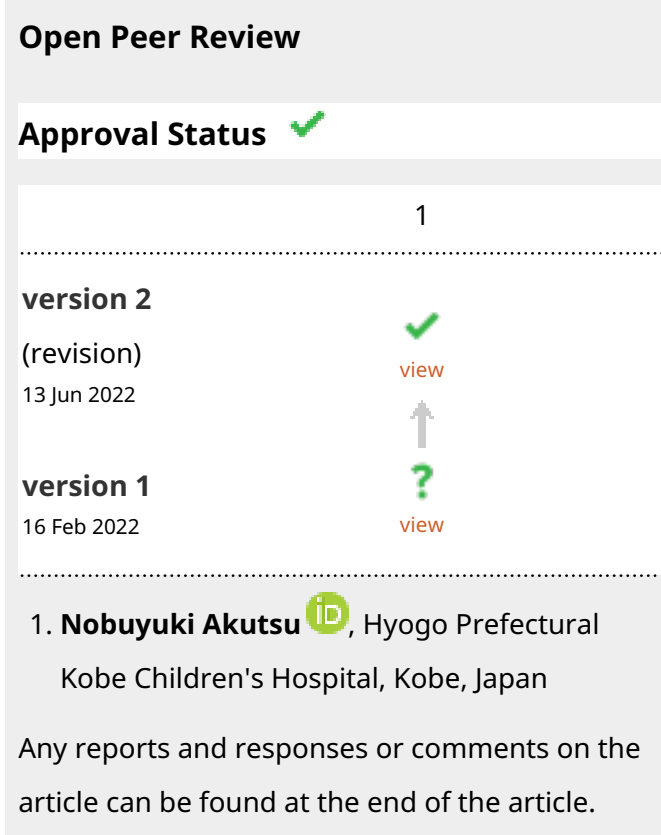




\section{Keywords}

Hydranencephaly, Cytomegalovirus infection, Ventriculoperitoneal

shunt

\section{Corresponding author: Cipta Pramana (pramanacipta@yahoo.com)}

Author roles: Dewiyanti L: Conceptualization, Data Curation, Funding Acquisition, Investigation; Diyo AR: Conceptualization, Data Curation, Investigation, Writing - Original Draft Preparation, Writing - Review \& Editing; Afandy JE: Funding Acquisition, Investigation, Writing - Original Draft Preparation; . J: Investigation, Visualization, Writing - Original Draft Preparation; Pramana C: Data Curation, Investigation, Supervision, Validation, Writing - Review \& Editing

Competing interests: No competing interests were disclosed.

Grant information: The author(s) declared that no grants were involved in supporting this work.

Copyright: @ 2022 Dewiyanti L et al. This is an open access article distributed under the terms of the Creative Commons Attribution License, which permits unrestricted use, distribution, and reproduction in any medium, provided the original work is properly cited.

How to cite this article: Dewiyanti L, Diyo AR, Afandy JE et al. Case Report: Hydranencephaly in a female newborn with congenital cytomegalovirus infection [version 1; peer review: 1 approved with reservations] F1000Research 2022, 11:199

https://doi.org/10.12688/f1000research.108934.1

First published: 16 Feb 2022, 11:199 https://doi.org/10.12688/f1000research.108934.1 


\section{Introduction}

Hydranencephaly is an uncommon congenital abnormality of the central nervous system. It is characterized by massive hemispheric necrosis and ventricular dilatation with most of the cerebral hemispheres being replaced by membranous sacs filled with cerebrospinal fluid (CSF). ${ }^{1,2}$ This abnormality is very rare and unique with an incidence rate of less than one per 10,000 births in the world.

Although there are many studies on hydranencephaly, some aspects of hydranencephaly are still being debated in terms of pathogenesis, onset, clinical manifestations, and prognosis. ${ }^{2}$ Intrauterine lesions to the bilateral supra-clinoid internal carotid arteries are thought to be the underlying pathophysiology of hydranencephaly, which leads to resorption of brain tissue usually supplied by the anterior circulation. Intrauterine infections and toxin exposure have been suggested as possible causes of these vascular damages. ${ }^{3}$ Congenital cytomegalovirus (CMV) infection can be one of the causes of hydranencephaly, but it is very rare. ${ }^{4}$ In a retrospective cohort study, macrocephaly (92\%) was the most common clinical manifestation of hydranencephaly, followed by seizures or myoclonic movements (41\%), and signs of increased intracranial pressure (ICP) $(25 \%){ }^{3}$

The choice of therapy for hydranencephaly including CSF diversion surgery is a challenge in itself because the prognosis is quite poor. ${ }^{3,5}$ Neural stem cell (NSC) transplantation therapy may be a new hope as an option for hydranencephaly therapy. ${ }^{6,7}$

We report a case of a female newborn with hydranencephaly and congenital cytomegalovirus infection and underwent a ventriculoperitoneal (VP) shunt procedure.

\section{Case report}

A female Javanese newborn was born from a 35-year-old mother, gravida 5, para 3, abortus 1 (G5P3A1), at the gestational age of 38 weeks. The baby was born by cesarean section on indication of suspected hydrocephalus with a birth weight of 3000 grams, body length $49 \mathrm{~cm}$, head circumference $35 \mathrm{~cm}$ and chest circumference $32 \mathrm{~cm}$, and an Appearance, Pulse, Grimace response, Activity, Respiration (APGAR) score of 8-9-10 at 1.5 and 10 minutes. The baby was born crying immediately, looked active, and did not appear cyanotic. The infant's primitive reflexes were intact at birth. The baby care after birth was performed in the perinatology room.

The mother did not partake in any antenatal care during pregnancy. She admitted that she did not have any complaints or flu-like syndrome during pregnancy. A family history of congenital abnormalities was denied. From her previous obstetric history, the mother had experienced abortion once during her second pregnancy with unknown causes.

On the second day, the baby looked less active, moaned, showed acral cyanosis, and had a large fontanelle that was dilated and soft. Signs of hydrocephalus such as Macewen's sign, setting sun phenomenon, and transillumination were found to be positive. From the babygram examination, neonatal pneumonia was suspected, while the echocardiographic examination indicated a floppy interatrial septum and mild mitral regurgitation (Figure 1). The non-contrast computerized tomography (CT) scan of the head showed a hypodense lesion according to the density of CSF filling the right and
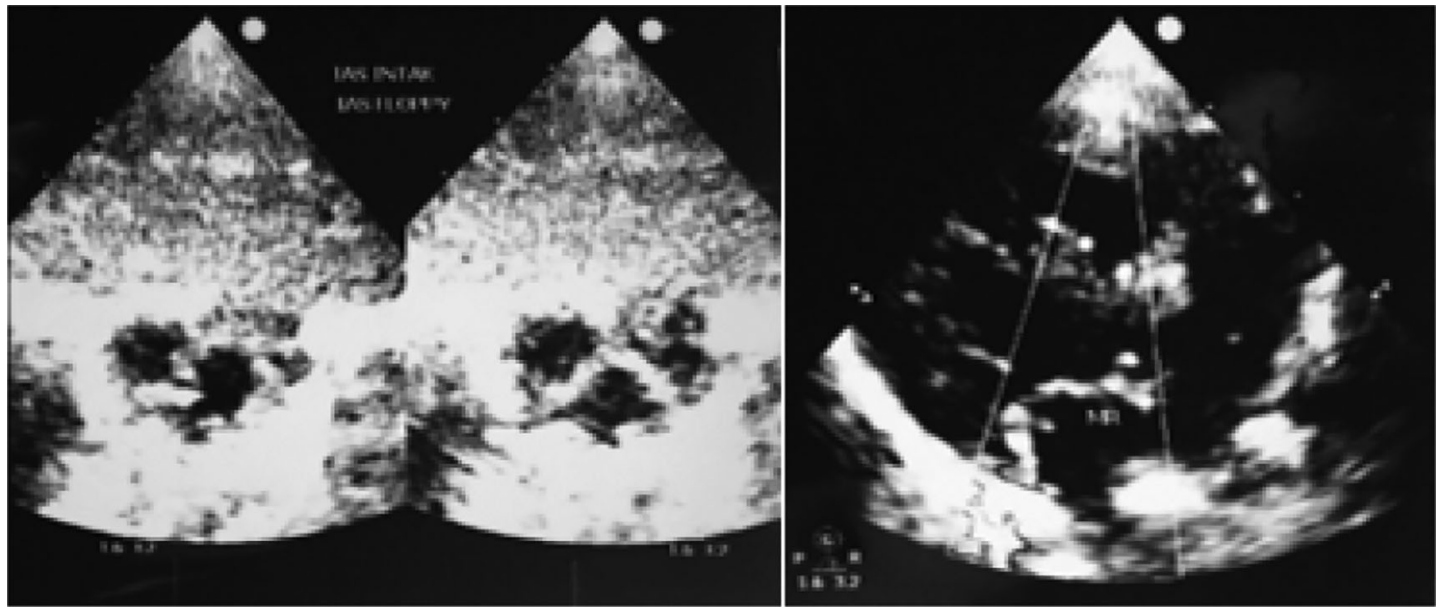

Figure 1. Echocardiography showed floppy interatrial septum and mild mitral regurgitation. 


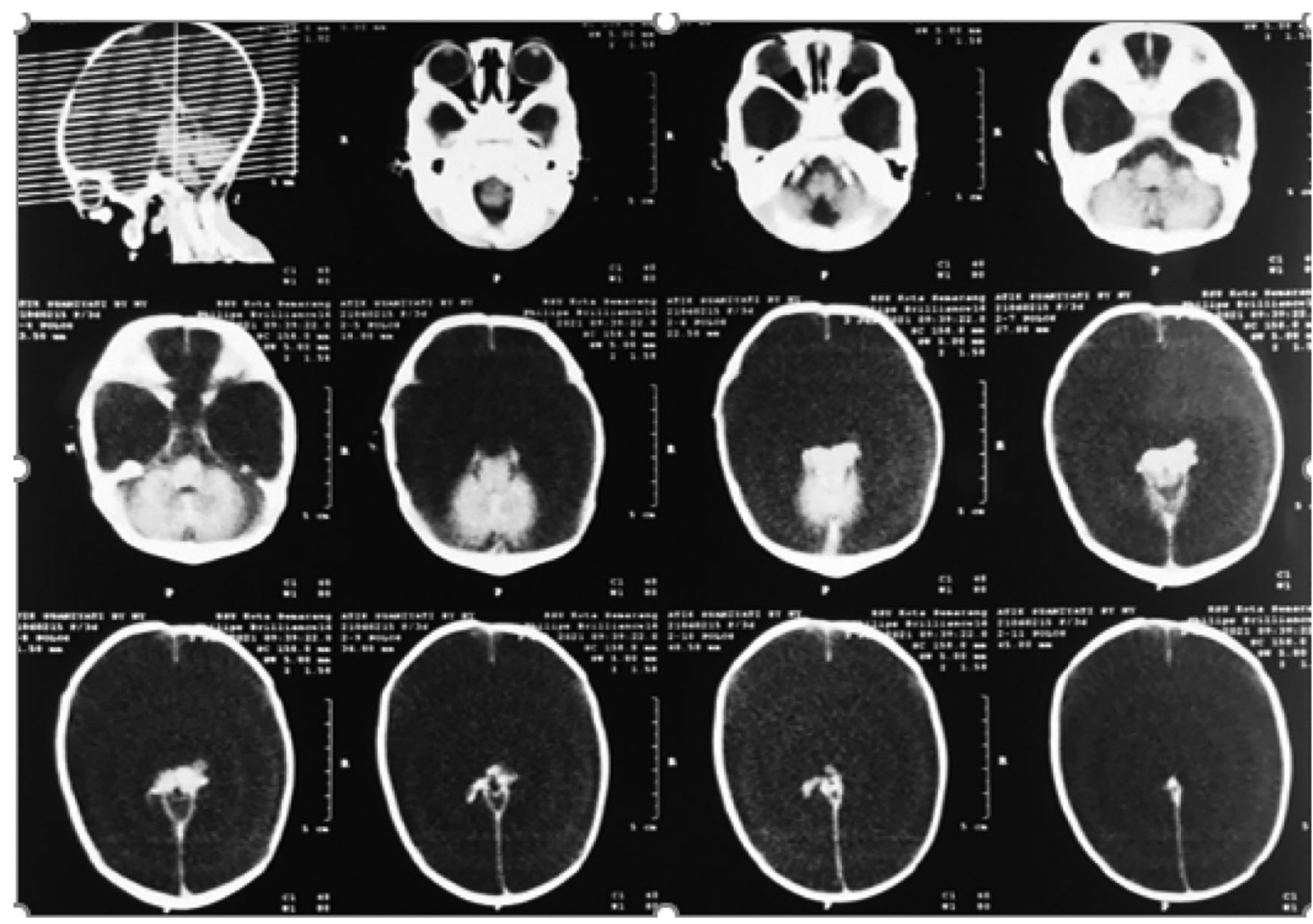

Figure 2. Non-contrast CT scan of the head indicated hydranencephaly. The structures of the right thalamus, mesencephalon, pons and posterior fossa, and the falx cerebri are still visible. CT, computerized tomography.

left hemicrania, while the hemi-cerebral cortex and lateral and third ventricles were not visible. Structures of the right thalamus, mesencephalon, pons and posterior fossa, and falx cerebri were still visible. The non-contrast CT scan of the head indicated hydranencephaly (Figure 2). From the toxoplasmosis, rubella, CMV, and herpes simplex virus (TORCH) screening examination, the results of anti-CMV immunoglobulin $\mathrm{G}(\mathrm{IgG})$ were $22 \mathrm{aU} / \mathrm{ml}$ (positive if the value $\geq 6$ ) and anti-CMV IgM were $0.156 \mathrm{COI}$ (negative if the value $\leq 0.7$ ).

On the 6th day, the baby had bradypnea and then apnea. The baby was then intubated with no. 3.5 endotracheal tube (ETT), $9 \mathrm{~cm}$ deep, and attached to mechanical ventilation with pressure control mode, inspiratory pressure (Pinsp) $13 \mathrm{cmH}_{2} \mathrm{O}$, positive end-expiratory pressure (PEEP) $8 \mathrm{cmH}_{2} \mathrm{O}$, respiratory rate (RR) 40 , fraction of inspired oxygen (FiO2) $80 \%$, and inspiratory expiratory ratio (I/E) 1:2. The baby care was moved to the neonatal intensive care unit (NICU) room. The baby seemed to have jitteriness.

After discussions with the patient's family, we decided to perform a VP shunt procedure. Head circumference before surgery was $36 \mathrm{~cm}$ (large for gestational age based on the Lubchenco curve). The VP shunt was performed with an opening pressure of $15 \mathrm{cmH}_{2} \mathrm{O}$. CSF was taken for macroscopic, chemical (protein, glucose, albumin), and microscopic (erythrocyte, leukocyte, foreign cell) analysis and the results were within normal limits.

After the VP shunt procedure was performed, the baby's general condition improved. The baby's head circumference was within normal limits according to the Lubchenco curve with an average of $33 \mathrm{~cm}$. Oxygen weaning was done gradually until the baby could breathe in room air on the 15th day of treatment. On day 16, the baby was discharged from the hospital with 3000 grams of body weight.

\section{Discussion}

Hydranencephaly is a condition in which there is no cerebral tissue because most of the brain's lining is damaged, fluid, and reabsorbed. The cerebral hemispheres are largely replaced by the thin-walled leptomeningeal sacs filled with CSF, preserving the structures of the midbrain and cerebellum. In hydranencephaly, there is a partial or complete falx cerebri 
structure with brainstem atrophy and the cerebellum is almost always normal, distinguishing it from holoprosencephaly. ${ }^{8,9}$ According to the patient in this case, brain structures other than the cerebral cortex were still visible.

In the absence of most of the cerebral cortex, the fetal head should be small. However, in some cases, the head is more often normal or enlarged because the choroid plexus in the lateral ventricles continues to produce CSF that cannot be adequately absorbed, causing an increase in pressure that can expand and impair the integrity of the ventricles and other intracranial structures. ${ }^{10}$

Several studies have stated that the onset of hydranencephaly is still debated and has not been proven. Most refer to the second trimester of pregnancy at 13 to 26 weeks after the hemispheres, ventricles, and falx cerebri are formed, followed by ischemic damage occurring in the third trimester, which usually causes multicystic encephalomalacia. ${ }^{2,8,11,12}$ However, there are also some case reports of hydranencephaly diagnosed before the 12th week of gestation, so hydranencephaly may occur in the first trimester of pregnancy. ${ }^{2,13-15}$

The cause of hydranencephaly remains unclear. Several hypotheses suggest vascular occlusion and infection be the causes of hydranencephaly. ${ }^{8}$ Occlusion of the supra-clinoid segment of the bilateral internal carotid artery is the most common cause, but this has not been confirmed because in some autopsies of hydranencephaly cases, the internal carotid arteries are not always occluded. ${ }^{5,8}$ Other causes include extensive tissue necrosis with cavitation, resorption of necrotizing tissue, and necrotic vasculitis caused by maternal exposure to carbon monoxide or butane gas. Intrauterine infections, such as congenital toxoplasmosis, CMV, and herpes simplex, can also cause local brain tissue damage. ${ }^{16}$ Hydranencephaly is not a malformation, but rather a secondary disorder of some pathological event, which causes ischemia in the uterus in the carotid artery area. ${ }^{5}$

The screening result of the patient in our case found evidence of congenital CMV infection. CMV target cells are immature cells of the germinal matrix that result in extensive periventricular inflammation, tissue necrosis, and dystrophic calcifications. In early pregnancy, neuronal migration anomalies can occur and subsequent infection can cause encephalopathic disorders, such as subependymal paraventricular cysts, hydranencephaly, and microencephaly. ${ }^{17}$

After CMV infects the fetus, several types of fetal cells allow CMV to replicate, including endothelial, epithelial, smooth muscle, and mesenchymal cells, as well as hepatocytes, monocytes or macrophages, and granulocytes. In further studies, CMV infection was also identified in several organs, such as the adrenal glands, bone marrow, diencephalon, small intestine, spleen, and heart. ${ }^{18}$ From the case presented in the current report, the patient also had cardiac abnormalities, which may have been caused by congenital CMV infection.

CMV-immunoglobulin $\mathrm{M}(\mathrm{IgM})$ antibodies are used as an indicator of acute infection, whereas IgG antibodies begin to appear after the onset of infection for several months. However, in cases of congenital infection, detection of CMV-IgG antibodies is complicated by the transplacental transfer of maternal antibodies. ${ }^{19}$ The results of the CMV antibody examination of the patient in this case report showed positive anti-CMV IgG with negative anti-CMV IgM, which supports the possibility that this infection was not an acute episode and was associated with the process of hydranencephaly. According to research from Chen et al., acquired anti-CMV IgG in infants disappears before the age of 8 months. ${ }^{20}$

Antiviral treatment should be given to infants with virologically confirmed congenital CMV infection. Intravenous ganciclovir and its orally available prodrug, valganciclovir, is the antiviral agent recommended for the treatment of congenital CMV disease. ${ }^{21}$ The patient in this case was not given antiviral treatment for CMV because the infection was not an acute episode.

Most babies with hydranencephaly die before birth. Infants that survive usually do not show visible neurological or clinical signs at first; primitive reflexes such as the sucking and swallowing reflexes, movements of the legs and arms are frequently present at birth. More specific symptoms, such as moaning, difficulty eating, hypotonia, or a dilated fontanelle, may also be present. After a few days, symptoms such as severe hypotonia, irritability, and seizures become more noticeable. ${ }^{5}$ The patient's initial signs found in this case report were that the baby looked normal at birth, but on the second day the large fontanelle dilated, movement became less active and on the 6th day, the patient appeared to have jitteriness.

Hydranencephaly has a poor prognosis because of the loss of most brainstem functions. Patients generally die before birth or within the first year of life. ${ }^{1}$ Treatment of hydranencephaly is only supportive and symptomatic, and the choice of therapy should be discussed with the family in detail. The failure of surgery to improve cognitive function must be balanced with stabilization of increased ICP and head size. The VP shunt procedure is an option but may require some repairs because there may be leakage from the hole site and absorption problems in the peritoneum. ${ }^{22}$ In this patient a VP shunt procedure was performed with consideration for stabilization of increased ICP and head size. 
The risk of complications of a VP shunt in infants with extreme macrocephaly is increased because of thinning and fragility of the scalp, malnutrition, and infected scalp ulcers. In infants with this condition, the choroid plexus coagulation procedure may be an option with a success rate of about $40 \%$, but it is still rarely performed in developing countries. ${ }^{23}$

NSC transplant therapy that has been successful in animal models is a new hope. ${ }^{7}$ Success is also seen in cerebral palsy patients with an effectiveness of about $50 \% .^{24,25}$ Hypothetically, cell junction pathology is the final common pathway of various genetic and environmental factors that cause disturbances in the ventricular zone (VZ). VZ disorders in the cerebral aqueduct cause hydrocephalus, while VZ disorders in the telencephalon cause abnormal neurogenesis. ${ }^{6}$ NSCs are known to have self-sustaining and pluripotent properties.

Proliferation and migration of neurons occur between the 12th and 30th weeks of gestation in humans, whereas in fetuses with hydrocephalus, VZ disturbances begin around the 16th week of gestation and continue throughout the second and third trimesters of gestation. ${ }^{6} \mathrm{NSC}$ transplant surgery is generally performed ex-utero after the child is born, but ideally, NSC transplantation is performed at an early stage of fetal development during the process of forming neurons in the cortex during VZ disruption. In-utero fetal surgery is a recent advancement that allows the operation to be safer by considering the safety of the mother and fetus, as well as avoiding premature delivery. ${ }^{7}$ Unfortunately, there are no facilities available at this time to accommodate the implementation of NSC transplantation at our location.

\section{Conclusions}

We report a case of hydranencephaly in a newborn with congenital CMV infection who underwent a VP shunt procedure. Hydranencephaly in our patient was a congenital central nervous system abnormality that may have been caused by intrauterine CMV infection. Despite having a poor prognosis, the patient improved after undergoing a VP shunt procedure. The success of NSC transplantation therapy in animal models and cerebral palsy patients may be a new hope for the treatment of hydranencephaly. Unfortunately, there are no facilities available at this time to accommodate the implementation of NSC transplantation at our location.

\section{Data availability}

All data underlying the results are available as part of the article and no additional source data are required.

\section{Consent}

Written informed consent for publication of their clinical details and clinical images was obtained from the parent of the patient.

1. Wijerathne BT, Rathnayake GK, Ranaraja SK: A rare variation of hydranencephaly: case report. F1000Res. 2014; 1: 22 PubMed Abstract | Publisher Full Text

2. Cecchetto G, Milanese L, Giordano R, et al.: Looking at the Missing Brain: Hydranencephaly Case Series and Literature Review. Pediatr. Neurol. 2013; 48(2): 152-158. PubMed Abstract | Publisher Full Text

3. Omar AT, Manalo MKA, Zuniega RRA, et al.: Hydranencephaly: Clinical Features and Survivorship in a Retrospective Cohort. World Neurosurg. 2020; 144: e589-e596. PubMed Abstract | Publisher Full Text

4. de Juan GA, Alemany Albert M, Marco Hernández AV, et al.: Neurological sequelae in patients with congenital cytomegalovirus. An Pediatría Engl Ed. 2020; 93(2): 111-117. Publisher Full Text

5. Pavone P, Praticò AD, Vitaliti G, et al.: Hydranencephaly: cerebral spinal fluid instead of cerebral mantles. Ital. J. Pediatr. 2014; 40(1):

PubMed Abstract | Publisher Full Text

6. Rodríguez EM, Guerra MM: Neural Stem Cells and Fetal-Onset Hydrocephalus. Pediatr. Neurosurg. 2017; 52(6): 446-461. PubMed Abstract | Publisher Full Text

7. Guerra M: Neural stem cells: are they the hope of a better life for patients with fetal-onset hydrocephalus?. Fluids Barriers CNS. 2014; $11(1): 7$.

PubMed Abstract | Publisher Full Text

8. Taori KB, Sargar KM, Disawal A, et al.: Hydranencephaly associated with cerebellar involvement and bilateral microphthalmia and colobomas. Pediatr. Radiol. 2011; 41(2): 270-273. PubMed Abstract | Publisher Full Text

9. Chinsky JM: Hydranencephaly: Transillumination may not illuminate diagnosis. NeoReviews. 2012; 13(4): e233-e240. Publisher Full Text

10. Pinar H: Hydranencephaly. Pathol Case Rev. 2011; 16(5): 186-188. Publisher Full Text

11. Vaneckova M, Seidl Z, Goldova B, et al.: Post-mortem magnetic resonance imaging and its irreplaceable role in determining CNS malformation (hydranencephaly) - Case report. Brain Dev. 2010; 32(5): 417-420.

PubMed Abstract | Publisher Full Text

12. Hahn JS, Lewis AJ, Barnes P: Hydranencephaly Owing to Twin-Twin Transfusion: Serial Fetal Ultrasonography and Magnetic Resonance Imaging Findings. J. Child Neurol. 2003; 18(5): 367-370.

PubMed Abstract | Publisher Full Text

13. Lam YH, Tang MHY: Serial sonographic features of a fetus with hydranencephaly from 11 weeks to term: Sonographic features of hydranencephaly. Ultrasound Obstet. Gynecol. 2000; 16(1): 77-79. PubMed Abstract | Publisher Full Text

14. Laurichesse-Delmas $H$, Beaufrère AM, Martin $A$, et al.: Firsttrimester features of Fowler syndrome (hydrocephalyhydranencephaly proliferative vasculopathy): Fowler syndrome. Ultrasound Obstet. Gynecol. 2002; 20(6): 612-615. PubMed Abstract | Publisher Full Text

15. Lin Y-S, Chang F-M, Liu C-H: Antenatal detection of hydranencephaly at 12 weeks, menstrual age.J. Clin. Ultrasound. 
1992; 20(1): 62-64

PubMed Abstract | Publisher Full Text

16. Khalid S, Zaheer S, Redhu N, et al.: Hydranencephaly: A rare cause of an enlarging head size in an infant. North. Am. J. Med. Sci. 2012; 4(10): 520.

Publisher Full Text

17. Sener RN: Congenital cytomegalovirus infection and hydranencephaly. Radiography. 1996; 2(3): 229-232. Publisher Full Text

18. Jones CA: Congenital cytomegalovirus infection. Curr. Probl. Pediatr. Adolesc. Health Care. 2003; 33(3): 70-93.

Publisher Full Text

19. Ross SA, Novak Z, Pati S, et al.: Diagnosis of Cytomegalovirus Infections. Infect. Disord. Drug Targets. 2011; 11(5): 466-474. PubMed Abstract | Publisher Full Text

20. Chen J, Hu L, Wu M, et al.: Kinetics of IgG antibody to cytomegalovirus (CMV) after birth and seroprevalence of antiCMV IgG in Chinese children. Virol. J. 2012; 9(1): 304. PubMed Abstract | Publisher Full Text

21. Harrison GJ: Current controversies in diagnosis, management, and prevention of congenital cytomegalovirus: Updates for the pediatric practitioner. Pediatr. Ann. 2015; 44(5): e115-e125. PubMed Abstract | Publisher Full Text

22. Sedain G, Rajbhandari B: Hydranencephaly: Insights into Pathophysiology and Management. Nepal J. Neurosci. 2020; 17(1): 5-9. Publisher Full Text

23. Shitsama $\mathrm{S}$, Wittayanakorn $\mathrm{N}$, Okechi $\mathrm{H}$, et al.: Choroid plexus coagulation in infants with extreme hydrocephalus or hydranencephaly: Clinical article.J. Neurosurg. Pediatr. 2014; 14(1): 55-57.

Publisher Full Text

24. Chen $G$, Wang $Y, X u$ Z, et al.: Neural stem cell-like cells derived from autologous bone mesenchymal stem cells for the treatment of patients with cerebral palsy. J. Transl. Med. 2013, 11(1): 21

PubMed Abstract | Publisher Full Text

25. He S, Luan Z, Qu S, et al.: Ultrasound guided neural stem cell transplantation through the lateral ventricle for treatment of cerebral palsy in children. Neural Regen. Res. 2012; 7(32): 2529-2535.

PubMed Abstract | Publisher Full Text 


\section{Open Peer Review}

\section{Current Peer Review Status: ?}

\section{Version 1}

Reviewer Report 20 May 2022

https://doi.org/10.5256/f1000research.120379.r124076

(c) 2022 Akutsu N. This is an open access peer review report distributed under the terms of the Creative Commons Attribution License, which permits unrestricted use, distribution, and reproduction in any medium, provided the original work is properly cited.

\section{Nobuyuki Akutsu}

Department of Neurosurgery, Hyogo Prefectural Kobe Children's Hospital, Kobe, Japan

Hydranencephaly is an uncommon congenital abnormality of the central nervous system. This article reported a rare case of a female newborn with hydranencephaly and congenital cytomegalovirus infection, who underwent a ventriculoperitoneal (VP) shunt procedure successfully.

This article was very interesting, but I think it needs some modifications and answers to the questions:

1. Did the patient need medical care at the time of discharge?

2. It is true that the prognosis of hydranencephaly is poor, but recently there have been many reports of prolonged survival. I would like you to mention that point, see the following article of mine: Akutsu et al., 2020.

3. The author described that choroid plexus coagulation (CPC) is still rarely performed in developing countries. However, isn't it difficult in developing countries to manage VP shunts? There are reports recommending CPC over VP shunts for the treatment of hydrocephalus in developing countries. (Warf, 2005).

Taking all these things into account, this paper will require minor revisions before indexing.

\section{References}

1. Akutsu N, Azumi M, Koyama J, Kawamura A, et al.: Management and problems of prolonged survival with hydranencephaly in the modern treatment era.Childs Nerv Syst. 36 (6): 1239-1243 PubMed Abstract | Publisher Full Text

2. Warf BC: Comparison of endoscopic third ventriculostomy alone and combined with choroid plexus cauterization in infants younger than 1 year of age: a prospective study in 550 African children.J Neurosurg. 2005; 103 (6 Suppl): 475-81 PubMed Abstract | Publisher Full Text

Is the background of the case's history and progression described in sufficient detail? Yes 
Are enough details provided of any physical examination and diagnostic tests, treatment given and outcomes?

Yes

Is sufficient discussion included of the importance of the findings and their relevance to future understanding of disease processes, diagnosis or treatment?

Yes

Is the case presented with sufficient detail to be useful for other practitioners?

Yes

Competing Interests: No competing interests were disclosed.

Reviewer Expertise: Pediatric neurosurgery

I confirm that I have read this submission and believe that I have an appropriate level of expertise to confirm that it is of an acceptable scientific standard, however I have significant reservations, as outlined above.

Author Response 30 May 2022

\section{Cipta Pramana}

Dear reviewer,

Thank you for taking the time to review our manuscript entitled "Case Report:

Hydranencephaly in a female newborn with congenital cytomegalovirus infection". We appreciate the time and effort dedicated by reviewers to provide feedback on our manuscript and are grateful for insightful comments and valuable improvements to our paper. We have included most of the suggestions made by reviewers in our revised version. Please see below, for point-by-point responses to reviewer comments.

1. "Did the patient need medical care at the time of discharge?"

Authors response: Yes. The patient fully recovered and was later discharged from the hospital weighing 3000 grams and scheduled for a follow-up examination and routine physical rehabilitation.

2. "It is true that the prognosis of hydranencephaly is poor, but recently there have been many reports of prolonged survival. I would like you to mention that point, see the following article of mine: Akutsu et al., 2020."

Author response: Yes. Hydranencephaly generally has a poor prognosis, however, there are several reports showing hydranencephaly patients able to survive for more than 5 years. The patient survival depends on the integrity of their brainstem function which controls cardiorespiratory function as well as temperature regulation.

3. "The author described that choroid plexus coagulation (CPC) is still rarely performed in 
developing countries. However, isn't it difficult in developing countries to manage VP shunts? There are reports recommending CPC over VP shunts for the treatment of hydrocephalus in developing countries. (Warf, 2005)."

Author response: According to several studies comparing CPC and ventriculoperitoneal shunt, it is shown that CPC has a higher success rate, however, due to the lack of neuroendoscopic facilities in developing countries such as Indonesia, especially in a rural area, a ventriculoperitoneal shunt was chosen in our study and showed improvement in patient's condition. It is not difficult to manage VP shunt in developing countries because the function and complication of the procedure are able to be closely monitored. The development of infrastructure, communication technology, and transportation allowed after-implant management to be performed well.

Competing Interests: The authors declare that they have no conflict of interest.

The benefits of publishing with F1000Research:

- Your article is published within days, with no editorial bias

- You can publish traditional articles, null/negative results, case reports, data notes and more

- The peer review process is transparent and collaborative

- Your article is indexed in PubMed after passing peer review

- Dedicated customer support at every stage

For pre-submission enquiries, contact research@f1000.com 